\title{
SCOPE OF SOCIAL MARKETING IN DE-MARKETING SMOKING HABITS: AN EXPLORATORY STUDY
}

\author{
SHAZEED AHMED \\ Assam Institute of Management, Assam, India \\ Corresponding author Shazeedahmd@gmail.com
}

\begin{abstract}
Social marketing is the art of marketing for the society. With the present environment confronted with numerous issues related to society and health, social marketing can be used as a humble way to address them. This study explores the scope of social marketing in de-marketing smoking habits. Consequently, it unveils the perception of consumers on the issue of smoking, and examine how people react on seeing a form of de-marketing advertisement on the cigarette packet. Finally, this paper provides suggestions for campaigns through social marketing to address the issue. This study is exploratory and descriptive in nature, involving a sample of 400 respondents. Factor analysis has been administered in analysing the data. This study reveals that people smoke due to addiction and out of the desire to socialize. Further, a section of smokers view smoking as having the capacity to relieve a person from depression. As far as seeing the de-marketing advertisement is concerned, smokers have a tendency to go for emotional forgetting as they simply ignore the statutory warning. These are vital input for social marketers to formulate policies. Social marketers involved in de-marketing campaigns can highlight that a person can achieve status in a society by virtue of exploiting one's own innovative skills and talents. Further positive contribution to the society gives one an eternal pleasure in life. Lastly marketers can pinpoint that regular exercise, good sleep, healthy diet and positive thinking can relieve oneself from stress.
\end{abstract}

Keywords: Social marketing, Statutory, De-marketing, Emotional forgetting.

Received: 01/4/2018

Revised: $23 / 7 / 2018$

\section{Introduction}

Social marketing is the process of devising, implementing and controlling programs to influence the acceptance of ideas which are social by nature. It is basically the art of using the skills of marketing to facilitate the conversion of efforts related to social action to a more productively planned and communicated program (Kotler \& Zaltman, 1971). Social marketing is also known as 'cause related marketing' as the primary purpose is for social good. It makes an effort to
Accepted: 27/12/2018

Published: 14/7/2019 
Often societies are confronted with undesirable practices related to attitudes, superstitions and behavior. One way to address them is by using the principles of social marketing. In fact today social marketing is applied in diverse fields around the world. Activities like disaster preparedness and response, conservation of ecosystem, addressing the need for literacy adequacy, corruption in the government machinery, health care quality improvement, awareness of health disparities and its remedy, need for healthy habits with proper sanitation, consumption for sustainability, measures for water treatment and the like, all have come under the purview of social marketing (Lefebvre, 2013).

Tobacco is a substance that contains nicotine. It is addictive in nature and found in cigarettes. It is this very substance whose intake through cigarettes turns people to a chain smoker. Most of the young people are not so conscious of the ill effects associated with the consumption of tobacco products in various forms. Consequently, it causes cancer which proves fatal in the long run. The World Health Organisation (WHO) Factsheet 2017 states that more than 7 million people die every year due to the consumption of tobacco. And out of those death, more than 6 million die due to the direct use of tobacco. The Report further reveals that among the smokers of the world, which is more than 1 billion, around 80 percent reside in the low and middle-income countries. The Indian Parliament passed COTPA Act 2003 (Cigarettes and Other Tobacco Products) to proscribe advertisement of, and to make provisions for the regulation of all activities related to trading, supply, production and distribution of cigarettes and other tobacco products in India.

De-marketing advertisements usually tries to dissuade users in the consumption of undesired products. Marketers often use de-marketing images as a statutory requirement in the sale of cigarette packets. In every packet of cigarette there is a printed message in a form like 'Smoking causes throat Cancer' which highlights the harmful effects of its consumption to health. These statutory warnings are in the form of a footnote on the face or on the back of the packet and often with the illustration of a cancer patient who is bruised from throat cancer. The question is whether these statutory warnings have been successful in dissuading each and every consumer from taking these harmful items of consumption.

With a broad idea on the concept and uses of social marketing against smoking across the world, a need is felt for the use of such a tool against smoking in an identified region of India which is prone to the habit of smoking. It has been felt necessary that before devising the contents of the messages to be used in social marketing, knowledge about the perception of smokers towards smoking and how they make interpretations of anti-smoking campaigns is essential.

Therefore, this study has been undertaken primarily with two objectives. The first objective is basically to seek the perception of consumers on the issue of smoking cigarettes. Secondly, the study tries to unveil how people react on seeing the statutory warning on the packet of cigarettes. Does the statutory warning has any effect in dissuading the consumers from taking cigarettes? Based upon the fulfillment of the objectives, this paper offers suggestions by using social marketing themes in anti-smoking campaigns.

\section{Literature Review}

Many studies have been conducted on social marketing in relation to the perception of smokers on the habit of smoking and de-marketing advertisements. One of the recent studies was conducted by Chauhan and Setia (2016) to find out the factors that motivate college going youngsters to smoke and find out if there is any relationship between their demographic 
background and socio-economic variables. The study found a direct relationship between smoking habit and income, and discovered that the students develop the habits of smoking due to influence from friends and classmates. The study is of the view that de-marketing efforts of the government does not yield much result. However there is a need for an all-inclusive demarketing efforts to make tobacco consumption least attractive and least available.

In another study, Lee et al. (2015) conducted a survey on the impact of the first anti-smoking campaign done nationally in Malaysia, known as TAK NAK (literally means don't want), on smokers. The campaign tried to target the cognitive (mental thoughts about the harmful effects of smoking), affective (increase of fear on the habit of smoking) and social (societal disapproval) domain. Using a sample of 2006 adult smokers, the study found that the targeted domains had effects on the association between TAK NAK impact and intentions to quit smoking. Hence, the study concluded that for effective campaigns, messages should target the cognitive, affective and social domain of the smokers to yield result.

Rennen et al. (2014) examined the relationship between tobacco control policy and social abhorrence towards smoking. It further examined whether social disapproval on smoking had an effect on the process of leaving the habit of smoking in three countries of Europe with a sample of 3865 respondents. The study found significant association between the knowledge on anti tobacco information with the sense of uncomfortable feeling of the smokers. The study also found that information campaigns against using tobacco had a positive impact on the reduction of smoking. However, role models of the societies are needed to carry out the antitobacco campaign to dissuade smokers from smoking.

Further, Neff et al. (2014) conducted a review on the usefulness of social marketing by evaluating the outcome from the 2014 Tips Campaign (against smoking). The campaign was divided into two phases of nine weeks each in the year 2014. The findings found that the campaign had a major effect on the behavior by de-motivating smokers to smoke. On the appraisal of the second phase of the campaign, it was found that more than 1.8 million smokers tried to get rid of the habit of smoking and about 104,000 smokers renounced smoking for a better life as a outcome of the campaign. Hence, sincere social marketing efforts are required to yield positive results.

Hong et al. (2013) carried out a research work to examine the helpfulness of advertising message and media against smoking habits in Malaysia. Using a questionnaire survey, the findings revealed that the respondents were nonpartisan on the messages related to anti-smoking advertisement campaigns with the exception, that of being affected by the fear message. The study also found that the impact of anti-smoking message varied with gender. However, a need was felt for the systematic content analysis of the messages used for advertisements.

In another study, Cengiz and Omay (2013) examined the effectiveness of health and social marketing campaigns in creating public consciousness against smoking and consumption of tobacco. The paper is of the view that the use of social marketing campaign against the use of tobacco by including the marketing mix, created a noble way to achieve the social goal. The use of marketing mix led to an effective movement with the correct policies along with media support. The paper concluded that the principles of social marketing enabled Turkey to achieve positive results in creating public awareness in the campaign against use of tobacco. Conversely a need was felt for framing targeted messages for targeted groups.

According to Farrelly et al. (2012), advertisements that de-market smoking with extremely moving and vivid content are quite effectual in inspiring 
smokers to give up smoking. They found that both the number and nature of advertisement seen by smokers had an impact on their probability of quitting smoking. In addition, exposure to emotional or graphic advertisements made a greater impact on the target. However, the effect of the advertisement was alike across education and income levels and at the same time for smokers who have changeable desires to stop smoking. It was suggested that further study be carried out on the role of emotional forgetting on smoking.

In their study on the influence of mass media campaigns on smokers, Durkin et al. (2012) found that anti-smoking campaigns had the capacity to stimulate the quitting behavior among adults. Communication that used graphic metaphors or testimonials to project the adverse effects on health for smoking were found to be very helpful at generating better and more knowledge, affirmative beliefs and quitting actions. Advertisements highlighting the harmful side of smoking on human health had a greater impact on the smokers belonging to the lower socio economic segment. Television was found to be the most useful electronic gadget so as to reach and persuade the adult smokers. There is scope to study as to why a section of people still smoke in spite of the graphic images or statutory warnings on the packets of cigarettes.

In the same vein, Mohaney (2010) examined the efficacy of campaigns against smoking which were targeted on the young generations. The study took a sample of 234 students to measure attitudinal reaction towards anti-smoking campaigns. It was found that global education programs through fear-based messages on consumers used to demotivate young people from smoking cigarette had mixed success. Mohaney (2010) was of the view that anti-smoking communications through social marketing can be successful in bringing changes in behavior if a twin policy of both communication and practical implementation is practiced.
In their research work on the use of visual warnings in social marketing against the use of tobacco in Europe, Gallopel-Morvan et al. (2009) tried to discover the most effective themes of health warnings and social messages. They were of the view that if fear appeals are used as a tool for social marketing, they need to be combined with self-effectiveness and discouraging messages as they provide avoidance reactions. However, there is a need for more effective social marketing in devising campaigns against the use of tobacco.

Khowaja et al. (2010) conducted a qualitative study on the evil practice of smoking. The researchers found that smokers know the risk of smoking but due to rampant advertisement by the tobacco industry, a majority of the smokers found it difficult to give up the habit. The study suggests that social marketing is a useful method to motivate smokers for maintaining sound health by avoiding the habit of smoking. This can be made possible by persuading smokers to voluntarily rethink about their smoking behavior. In fact, adequate scope is there to fundamentally focus on the use of social marketing to campaign against smoking.

Jessor (2007) explored the challenges faced by social marketers in the process of motivating people to do away with harmful and socially unacceptable practices like smoking tobacco. The study is of the opinion that the most significant way to dissuade people to stop smoking is through legislations which ban smoking in workplace and enclosed public work places. The study is of the view that the use of social marketing by the governments of countries like Scotland, Wales, Northern Ireland and England to stop smoking denotes an exemplary change in the process of changing public opinion and social norms.

Hershey et al. (2005) examined how exposure to truth acts as a barrier to the long-established beliefs as well as attitudes toward smoking which is created by massive industry media campaigns. Using both pretest and post-test 
method on a sample of 16000 respondents, the study found that youths with greater exposure to advertisement campaigns reacted more negatively in terms of belief and attitude towards tobacco industry The study provided a model for social retention of the beliefs as it was found that negative attitudes towards the industry is associated with lesser interest on advertisements that promote tobacco and smoking behavior. However, there is a need to study the issue of clutter effect in advertisements.

Generally, the above studies make an assessment of anti-smoking efforts in different geographical areas through social marketing, and some deal with advertisement themes and their effects. However, research works on identifying the specific reasons for smoking and the perceptual dimension involved in interpreting specific demarketing advertisements are quite rare. This study attempts to narrow the gap.

\section{Research Methods}

This study comprised of both exploratory and descriptive research. It was conducted in the city of Guwahati which is regarded as the gateway of North East India. The population comprised of cigarette smokers who were majors. A sample size of 400 respondents was taken using simple convenience and judgment sampling technique. Data collection was done through direct face to face personal interviews and a structured questionnaire was used. Background information of the respondents with respect to age, academic qualification and profession is shown in Table 1.

Table 1

Background of Respondents

\begin{tabular}{lrc}
\hline Age & Frequency & Percentage (\%) \\
\hline $18-24$ & 75 & 18.75 \\
$25-34$ & 102 & 25.50 \\
$35-44$ & 95 & 23.75 \\
$45-54$ & 78 & 19.50 \\
55 and above & 50 & 12.50 \\
\hline Total & 400 & 100.00 \\
\hline Academic Qualification & & \\
\hline Below 10 & \\
$10^{\text {th }}$ Level & & 17.75 \\
$12^{\text {th }}$ Level & 71 & 22.00 \\
Graduate level & 88 & 25.50 \\
Post-Graduate level & 102 & 20.50 \\
\hline Total & 82 & 14.25 \\
\hline & 57 & 100.00 \\
\hline Profession & 400 & \\
\hline Student & & 15.25 \\
Government employee & & 14.25 \\
Private employee & 61 & 19.75 \\
Self-employed in business & 57 & 27.75 \\
Self-employed professional & 79 & 23.00 \\
\hline Total & 111 & 100.00 \\
\hline
\end{tabular}


In fulfilling the first objective of the study (perceptions on issues of smoking), a total of 10 attitudinal statements related to perception of consumers on smoking was developed and used as a perception scale on smoking. Originally 15 items (statements) were developed based upon initial focus group interview with smokers, reviewed articles and self-intuition.
Later, the redundant ones were dropped and the total items were brought down to 10 . The statements are depicted in Table 2 (Perception Scale on Smoking). A 5-point Likert scale was used to measure their agreement with each of the items, where 5 indicates strongly agree, 4 agree, 3 neither agree nor disagree, 2 disagree and 1 strongly disagree.

Table 2

Perception Scale on Smoking and Reliability Measure Score

\begin{tabular}{|c|c|c|}
\hline CODES & STATEMENTS (ITEMS) & Cronbach's Alpha \\
\hline S1 & Smoking is my social need & \\
\hline $\mathrm{S} 2$ & Smoking comforts me when I am depressed & \\
\hline S3 & Smoking gives me pleasure and makes me feel good & 0.728 \\
\hline S4 & Smoking helps me to celebrate something & \\
\hline S5 & Smoking helps me to manage stress & \\
\hline S6 & Smoking is preferred while driving my car & \\
\hline S7 & Smoking is my addiction & \\
\hline S8 & Smoking enhances my overall personality; & \\
\hline S9 & Smoking is a status symbol for me & \\
\hline S10 & Smoking increases my concentration & \\
\hline
\end{tabular}

To test the reliability of the scale, Cronbach's Alpha was used. A score of 0.728 (shown in Table 2), which is greater than 0.6 (Nunnally, 1976) shows that the reliability of the scale has been established.

In achieving the second objective (that is to examine respondents' reactions on warnings on cigarette packets) a total of 7 attitudinal statements related to perception of consumers on de-marketing advertisements have been developed and used as perception scale on demarketing advertisement. Initially, there were 12 items; however, 5 were found redundant and dropped. The statements are shown in Table 3. Again, the same 5-point Likert scale was used to measure the respondents' perception. The Cronbach's Alpha of 0.787 shows that the scales are reliable and acceptable.

In analyzing the data, mean values and factor analysis were used. Mean value has been derived by summing up all the ratings given by each respondent on a particular variable or criteria and then dividing the total value by the total number of respondents. Factor Analysis is used as a data reduction method. It tries to access the influence of a few unobserved variables called factors on a large number of observed variables. 
Table 3

Perception Scale on De-Marketing Advertisement and Reliability Measure Score

\begin{tabular}{clc}
\hline CODES & \multicolumn{1}{c}{ STATEMENTS } & $\begin{array}{c}\text { Cronbach's } \\
\text { Alpha }\end{array}$ \\
\hline S1 & The statutory warning does not matter with my addiction \\
S2 & $\begin{array}{l}\text { When so many people are consuming it including me for years without any bad } \\
\text { affect, it does not matter }\end{array}$ & 0.787 \\
S3 & $\begin{array}{l}\text { These statutory warning are for children and not for adults like us } \\
\text { S4 }\end{array}$ & $\begin{array}{l}\text { It is my life. You have it or you do not have it, it is your decision } \\
\text { S5 }\end{array} \quad \begin{array}{l}\text { When I consume, I ignore the warning and I do not even look into the Cancer } \\
\text { patient in the packet }\end{array}$ \\
S6 & $\begin{array}{l}\text { When the call of death comes, no one can escape, no matter whether you smoke } \\
\text { or not } \\
\text { S7 }\end{array}$ & $\begin{array}{l}\text { The statutory warning is true and I would have stopped the habit if I had thought } \\
\text { over it deeply. }\end{array}$ \\
\end{tabular}

\section{Results}

\section{Perception towards Smoking}

Table 4 shows the mean scores for all the items on perception towards smoking. It is found that Statement 1 (smoking is my social need), with a mean score of 4.84, Statement 7 (smoking is my addiction) with a mean score of 4.77 , and Statement 2 (Smoking comforts me when I am depressed) with a mean score of 3.88 received the highest ratings.

Table 4

Perception Scale on De-Marketing Advertisement and Reliability Measure Score

\begin{tabular}{clc}
\hline SI. No. & STATEMENTS & Mean Score \\
\hline S1 & Smoking is my social need & 4.84 \\
S2 & Smoking comforts me when I am depressed & 3.88 \\
S3 & Smoking gives me pleasure and makes me feel good & 3.30 \\
S4 & Smoking helps me to celebrate something & 3.79 \\
S5 & Smoking helps me to manage stress & 2.67 \\
S6 & Smoking is preferred while driving my car & 2.75 \\
S7 & Smoking is my addiction & 4.77 \\
S8 & Smoking enhances my overall personality & 2.04 \\
S9 & Smoking is a status symbol for me & 2.77 \\
S10 & Smoking increases my concentration & 2.68 \\
\hline
\end{tabular}


Further, factor analysis was conducted to reduce the number of factors identified, so as to extract the most important factors out of a total number of pre-selected factors. The different perceptual statement (constructs) on smoking has been identified as factors (or items), and the 10 statements are used as factors (or items).
The output of the factor analysis is obtained by requesting the Principal Component Analysis. Details of the output are given in Tables 5 (Factor Matrix), 6 (Final Statistics) and Table 7 (Rotated Factor Matrix). Table 6 comprises the communality for all 10 variables and the Eigen value of all factors which have Eigen value of 1 or more.

Table 5

Factor Matrix

\begin{tabular}{llccc}
\hline S1. No. & \multicolumn{1}{c}{ Variable } & Factor 1 & Factor 2 & Factor 3 \\
\hline S1 & Smoking is my social need & .077 & .449 & .188 \\
S2 & Smoking comforts me when I am depressed &. $\mathbf{6 5 4}$ & .129 & .069 \\
S3 & Smoking gives me pleasure and makes me feel good & .131 &. $\mathbf{7 7 0}$ & .085 \\
S4 & Smoking helps me to celebrate something & .282 & .173 & .069 \\
S5 & Smoking helps me to manage stress &. $\mathbf{5 8 1}$ & .085 & .032 \\
S6 & Smoking is preferred while driving my car & .343 & -.015 & .274 \\
S7 & Smoking is my addiction & .485 & $\mathbf{. 6 0 2}$ & .027 \\
S8 & Smoking enhances my overall personality & -.117 & .419 & $\mathbf{. 7 2 4}$ \\
S9 & Smoking is a status symbol for me & .268 & .184 & $\mathbf{. 7 0 6}$ \\
S10 & Smoking increases my concentration & .079 & .015 & $\mathbf{. 5 0 7}$ \\
\hline
\end{tabular}

Table 6 shows the final statistics. Before extraction, it is assumed that each of the original variables has an Eigen value $=1$. Consequently there are many factors. But since an attempt is made to extract the least amount of factors possible which will maximize the explained variance, factors with Eigen value that is equal to or more than 1 is considered. It has been found that there are three factors which have Eigen value of 1 or more than 1 . The last column in the table (cumulative percentage) shows that the 3 factors extracted together account for 70.223 percent of the total variance. 
Table 6

Final Statistics

\begin{tabular}{lccccc}
\hline Sl. No. & Communality & Factor & Eigen value & \% of Variable & Cum \% \\
\hline Factor 1 & .389 & 1 & 3.912 & 22.256 & 22.256 \\
Factor 2 & .587 & 2 & 1.519 & 24.095 & 46.351 \\
Factor 3 & .689 & 3 & 1.179 & 23.872 & 70.223 \\
Factor 4 & .335 & & & & \\
Factor 5 & .574 & & & & \\
Factor 6 & .433 & & & & \\
Factor 7 & .792 & & & \\
Factor 8 & .847 & & & \\
Factor 9 & .799 & & & \\
Factor 10 & .453 & & & & \\
\end{tabular}

Table 7

Rotated Factor Matrix

\begin{tabular}{clccc}
\hline S1. No. & \multicolumn{1}{c}{ Variable (Statement) } & Factor 1 & Factor 2 & Factor 3 \\
\hline S1 & Smoking is my social need & .124 & $\mathbf{. 7 1 9}$ & .302 \\
S2 & Smoking comforts me when I am depressed & $\mathbf{. 8 5 4}$ & .169 & .090 \\
S3 & Smoking gives me pleasure and makes me feel & .158 & $\mathbf{. 9 2 8}$ & .102 \\
& good & .487 & .299 & .120 \\
S4 & Smoking helps me to celebrate something & .766 & .112 & .042 \\
S5 & Smoking helps me to manage stress & .522 & -.023 & .416 \\
S6 & Smoking is preferred while driving my car & .545 & $\mathbf{. 6 7 6}$ & .030 \\
S7 & Smoking is my addiction & -.127 & .456 &. $\mathbf{7 8 7}$ \\
S8 & Smoking enhances my overall personality & .300 & .206 & $\mathbf{. 7 8 9}$ \\
S9 & Smoking is a status symbol for me & .117 & .022 & $\mathbf{. 7 5 3}$ \\
S10 & Smoking increases my concentration & & & \\
\hline
\end{tabular}

Table 8 (Comparison of Factor Matrix Table and Rotated Factor Matrix Table) reflects the comparison of Factor Matrix (Table 5: Factor Matrix) and Rotated Factor Matrix (Table 7: Rotated Factor Matrix) with the high loading Statements and their loadings. It has been observed that as per Table 5 for Factor 1, Statement 2 and Statement 5 have high loadings. But as per Table 7 for the same Factor 1, Statement 2, Statement 5 and Statement 7 have high loading. Finding out the statements of common occurrence, it can be concluded that Factor 1 is dominated by Statement 2 and Statement 5. Similarly Factor 2, based upon common occurrence, is dominated by Statement 1, Statement 3 and Statement 7. But Statement 7, has cross loadings on both Factor 1 and Factor 2 with 0.545 and 0.676 respectively (as per Table 7: Rotated Factor Matrix). But since the load is higher on Factor 2 and based on theoretical and measurement considerations, Statement 
7 is considered for Factor 2. Further, Factor 3, based upon common occurrence is dominated by Statement 8, Statement 9 and Statement 10. But Statement 8 has cross loadings on both Factor 2 and Factor 8 with 0.456 and 0.787 respectively (as per Table 7: Rotated Factor Matrix). But since the load is higher on Factor 3 and based on theoretical and measurement considerations, Statement 8 is considered for Factor 3 .

Table 8

Comparison of Factor Matrix Table and Rotated Factor Matrix Table

Table No.

\section{HIGH LOADING STATEMENTS / LOADINGS}

Factor 1

Factor 2

Factor 3

\begin{tabular}{lccc}
\hline $\begin{array}{l}\text { Table 5: } \\
\text { Factor Matrix }\end{array}$ & S2/0.654, S5/0.581 & $\begin{array}{l}\text { S1/0.449, S3/0.770, } \\
\text { S7/0.602 }\end{array}$ & $\begin{array}{l}\text { S } 8 / 0.724, \text { S } 9 / 0.706, \\
\text { S10/0.507 }\end{array}$ \\
$\begin{array}{lccc}\text { Table 7: } \\
\text { Rotated F. Matrix }\end{array}$ & $\begin{array}{l}\text { S2/0.854, S5/0.766, } \\
\text { S7/0.545 }\end{array}$ & $\begin{array}{l}\text { S1/0.719, S3/0.928, } \\
\text { S7/0.676, S } 8 / 0.456\end{array}$ & $\begin{array}{l}\text { S8/0.787, S } 5 / 0.789, \\
\text { S10/0.753 }\end{array}$ \\
COMMON STATEMENTS & S2 and S5 & S1, S3 and S7 & S8, S9 and S10 \\
\hline
\end{tabular}

As there is no clear-cut guidelines, in terms of cut-off for high loadings, 0.55 is taken as the cut- off for high values arbitrarily and keeping in mind the related statements of the problem under consideration. From Table 7 of the Rotated Matrix, it has been found that for Factor 1, Statement 2 (smoking comforts me when I am depressed) and Statement 5 (smoking helps me to relieve from stress) has loadings of 0.854 and 0.766, respectively. It suggests that Factor 1 is a combination of these two original variables. At this point, in order to assimilate the core of the original variables, which continues to form the underlying concept, a suitable theme named as 'An injurious stress reliever' is used.

For Factor 2, Statement 1 (Smoking is my social need), Statement 3 (Smoking gives me pleasure and makes me feel good) and Statement 7 (Smoking is an addiction) have loadings of $0.719,0.928$ and 0.676 , respectively. It suggests that Factor 2 is a combination of these three original variables. In order to assimilate the core of the original variables, which continues to form the underlying concept, a suitable theme named as 'An undesired lifestyle item' is used.

For Factor 3, Statement 8 (Smoking enhances my overall personality), Statement 9 (Smoking is a status symbol for me) and Statement 10 (Smoking increases my concentration) have loadings of $0.787,0.789$ and 0.753 , respectively. The loading of the three statements are fairly close on magnitude. It suggests that Factor 3 is a combination of these three original variables. In order to assimilate the core of the original variables, which continues to form the underlying concept, a suitable theme named as 'An unhealthy benefit seeker' is used.

\section{Reaction towards Warning on Cigarette Packets}

Every packet of cigarette has a message which reads as 'Smoking causes throat Cancer' with a pictorial representation of a bruised person suffering from throat cancer. In investigating as to whether the statutory warning on the packet 
Table 9

Mean Score of Statements on Perception towards De-Marketing Advertisement

\begin{tabular}{llc}
\hline \multicolumn{1}{c}{ STATEMENT } & Mean Score \\
\hline S1 & The statutory warning does not matter with my addiction. & 4.13 \\
S2 & $\begin{array}{l}\text { When so many people are consuming it including me for years without any bad affect, } \\
\text { it does not matter. }\end{array}$ & 3.07 \\
S3 & These statutory warning are for children and not for adults like us. & 3.19 \\
S4 & It is my life. You have it or you do not have it, it is your decision. \\
S5 & $\begin{array}{l}\text { When I consume, I ignore the warning and I do not even look into the Cancer patient } \\
\text { in the packet. }\end{array}$ & 4.45 \\
S6 & When the call of death comes, no one can escape, no matter whether you smoke or not & 3.25 \\
\hline
\end{tabular}

has any effect, the respondents are expected to indicate their perception on the seven statements with appropriate ratings. The mean scores of each of the items is depicted in Table 9.

It has been found that Statement 5 (When I consume, I ignore the warning and I do not even look into the Cancer patient in the packet) with a mean score of 4.45 and Statement 1 (The statutory warning does not matter with my addiction) with a mean score of 4.13 received the highest ratings. From the findings it can be inferred that smokers ignore the warning and do not even look into the cancer patient in the packet. Further the statutory warning does not make any significant impact in changing the addictive nature of the smokers.

\section{Discussion}

This study reveals that consumers smoke cigarettes because they are addicted to smoking. Secondly, consumers smoke out of their desire to socializing while smoking. Thirdly, a segment of the smokers believe that smoking can relieve an individual from depression.

This study also finds that the smokers normally ignore the statutory warnings given in cigarette packets. They do not even pay attention to the cancer patient in the cigarette packet. Further, the statutory warning cannot be regarded as significantly instrumental in discouraging the smokers from further smoking. In guise, smokers have a tendency to go for emotional forgetting by simply ignoring the statutory warning in the cigarette packet. This happens through selective distortion of the message in the process.

The findings of the study provide vital inputs for social marketers in the formulation of social message themes against the habit of smoking. Suggestions are provided for exploring the scope of using social marketing in anti-smoking campaigns. It is the task of social marketers to devise befitting advertising themes by using the perceptual information derived from the study so as to dissuade smokers from smoking as given below; 
An unhealthy Highlight that an individual can achieve status in a society by virtue of exploiting benefit seeker one's own innovative skills and talents. Personality is a reflection of rational thinking and constructive behaviour. Good habits lead to good health and this ultimately leads to increase of concentration in the mind.

An undesired Underscore that smokers can have better alternatives to socialize. Smoking puts life lifestyle item to risk in the long run. Pinpoint the importance of dependents along with the near and dear ones of smokers. It is not fulfillment of self-desires that gives one pleasure but rather what one gives back to the society. It gives eternal pleasure in life and held as a form of charity.

An injurious Emphasize that smoking does not free an individual from stress. Rather, it increases stress the stress level. There are other healthy and productive ways to relieve oneself from reliever stress. Regular exercise, good sleep, healthy diet and positive thinking are the golden principles to relieve oneself from stress.

\section{Conclusion}

Smoking is an evil practice that retards the growth and development of a society. It is a habit without any empirically proven health benefit. There are many prejudices that prevail among smokers on the logic of taking cigarettes. But these are biased and factually unfounded. It is the task of social marketers to see that societies are made literate in matters of biased beliefs on diverse issues concerning any society and especially in relation to smoking habits. In fact, they can use social marketing to motivate people to shun bad habits and undesirable practices. This is a requirement to move societies forward in the positive direction and make the world a better place to live in.

This study was conducted during the second and third quarter of 2017. With the passage of time, there may be changes in the perception of smokers on smoking and on de-marketing advertisements. At the same time the findings of the study cannot be generalized and may vary from region to region as well as from country to country on the basis of values, beliefs, climatic conditions and standard of lifestyle. Further studies can be carried to explore the scope of using social marketing to address other important issues like binge drinking, rash driving of motor vehicles by teenagers, excessive use of mobile phones, erosion of the reading and writing habits of the students community and degradation of moral values in the society.

\section{References}

Cengiz, E., \& Omay, E. G. G. (2013). Marketing health and social marketing the importance of Public Health Campaigns to create public awareness in Turkey. Mediterranean Journal of Social Sciences, 4(10), doi:10.5901/mjss.2013. v4n10p325.

Chauhan, H., \& Setia, P. (2016). Discouraging cigarette smoking through de-marketing strategies. Future Business Journal, 2(1), 31-39, doi:10.1016/j.fbj.2016.01.002.

COTPA ACT 2003, The Gazette of India, Registered no. DL-33004/2003, No 37. New Delhi, Monday, May 19, 2002, Published by Ministry of Law and Justice (Legislative Department, Government of India)

Durkin, S., Brenna, E. \& Wakefield, M. (2012). Mass media campaigns to promote smoking cessation among adults: An 
integrative review. Tobacco Control, 21, 127-138.

Farrelly, M. C., Duke, J. C., Davis, K. C. \& Juster, H. R. (2012). Promotion of smoking cessation with emotional and/or graphic anti smoking advertising, American Journal of Preventive Medicine. 43(5), doi: 10.1016/j.amepre.2012.07.023

Gallopel-Morvan, K., Gabriel, P., Gall-Ely, M. L., Rieunier, S. \& Urien B. (2009). The use of visual warnings in social marketing: The case of tobacco. Journal of Business Research, 06889, 5, xxx (2009) xxx-xxx, doi:10.1016/j.jbusres.2009.09.012.

Hershey, J. C., Niederdeppe, J., Evans, W. D., Nonnemaker, J., Blahut, S., Holden, D. \& Haviland, M. L. (2005). The theory of truth: How counter industry campaigns affect smoking behavior among teens. Health Psychology, 24(1), 22-31, doi: 10.1037/0278-6133.24.1.22.

Hong, Y. H., Soh, C. H., Khan, N., Abdullah, M. M. B., \& Teh, B. H. (2013). Effectiveness of Anti-Smoking Advertising: The roles of message and media. International Journal of Business and Management; 8(19); Published by Canadian Center of Science and Education, 04(10). doi:10.5539/ijbm.v8n19p55.

Jessor, B. (2007). Creating a demand for better health by using social marketing techniques. The Pharmaceutical Journal, doi: 10.1007/s13187-0100088-8, https://www.ncbi.nlm.nih.gov/ pubmed/20238199.

Khowaja, L. A., Khuwaja, A. K., Nayani, P., Jessani, S., Khowaja, M. P., \& Khowaja, S. (2010). Quit smoking for life social marketing strategy for youth: A case for Pakistan. J Cancer Educ. US National Library of Medicine National Institutes of Health, 25(4), 637- 42. doi: 10.1007/ s13187-010-0088-8.

Kotler, P., \& Zaltman, G. (1971). Social marketing: An approach to planned social change. Journal of Marketing, 35, 3-12.
Kotler, P., \& Levy, S. (1971). Demarketing, yes, demarketing. Harvard Business Review: November-December, 74-80.

Lamb, C. W., Hair, J. F., \& McDaniel, C. (2010). Essentials of Marketing. Cengage Learning. 76, ISBN 0538478349.

Lee, W. B., Fong, G. T., Dewhirst, T., Kennedy, R. D., Yong, H., \& Borland, R. (2015). Social marketing in Malaysia: Cognitive, affective, and normative mediators of the TAK NAK anti-smoking advertising campaign. Journal of Health Communication 20(10):1-11, doi: 10.1080/10810730.2015.1018565.

Lefebvre, R. C. (2013). Social marketing and social change: Strategies and tools for improving health, well-being and the environment. San Francisco: JosseyBass.

Mohaney, J. (2010). Strategic communication and anti-smoking campaigns. Public Communication Review, 1(2), 33-48.

Neff, L. J., Patel, D., Davis, K., Ridgeway, W., \& Shafer, P., \& Cox, S. (2014). Evaluation of the National Tips from Former Smokers Campaign: The 2014Longitudinal Cohort. Preventing Chronic Disease, 13(42).

Nunnally, J. C. (1967). Psychometric Theory, New York: McGraw-Hill.

Rennen, E., Nagelhout, G. E., Putte, B., Janssen, E., Mons, E., Guignard, R., Beck, F., Vries, H., Thrasher, J. F., \& Willemsen, M. C. (2014). Associations between tobacco control policy awareness, social acceptability of smoking and smoking cessation. Health Education Research, 29(1), 72-82, doi: 10.1093/her/cyt073.

World Health Organisation (WHO) Factsheet 2017, retrieved from http://www.who.int/ mediacentre/factsheets/fs339/en. 
